\title{
Gambogenic acid induces proteasomal degradation of CIP2A and sensitizes hepatocellular carcinoma to anticancer agents
}

\author{
XIAN-JUN YU ${ }^{1-3 *}$, QUN ZHAO $^{2 *}$, XUAN-BIN WANG $^{1}$, JING-XUAN ZHANG $^{1}$ and XIAO-BO WANG ${ }^{3}$ \\ ${ }^{1}$ Laboratory of Chinese Herbal Pharmacology, Oncology Center, Renmin Hospital and School of Basic Medical Sciences, \\ Hubei University of Medicine, Shiyan, Hubei 442000; ${ }^{2}$ Key Laboratory of Nutrition and Metabolism, \\ Institute for Nutritional Sciences, Shanghai Institutes for Biological Sciences, Graduate School of the \\ Chinese Academy of Sciences, Chinese Academy of Sciences, Shanghai 200031; ${ }^{3}$ Center for Translational Medicine, \\ Suizhou Hospital, Hubei University of Medicine, Suizhou, Hubei 441300, P.R. China
}

Received March 17, 2016; Accepted May 11, 2016

DOI: $10.3892 /$ or.2016.5188

\begin{abstract}
Cancerous inhibitor of protein phosphatase 2A (CIP2A) is an oncoprotein that is overexpressed in many human malignancies. It regulates phosphorylated AKT and stabilizes c-Myc in cell proliferation and tumor formation, suggesting that CIP2A plays an essential role in the development of cancer. In the present study, we report that a natural compound, gambogenic acid (GEA), induced the degradation of CIP2A via the ubiquitin-proteasome pathway. Interestingly, the combination of GEA and proteasome inhibitors potentiated the accumulation of ubiquitinated CIP2A and aggresome formation. In addition, GEA exhibited an inhibitory effect on cell proliferation and CIP2A-downstream signaling molecules (c-Myc and pAKT). Furthermore, GEA and CIP2A silencing enhanced the chemosensitivity of hepatocellular carcinoma cells to anticancer agents, suggesting that a combination of a CIP2A inhibitor and anticancer agents could be a valuable clinical therapeutic strategy. These results indicate that GEA is a CIP2A inhibitor that interferes with the ubiquitination and destabilization of CIP2A, providing a promising strategy to enhance the combinational therapy for hepatocellular carcinoma.
\end{abstract}

\section{Introduction}

Human hepatocellular carcinoma (HCC) is one of the most common malignant tumors worldwide and ranks third in terms of global cancer-related mortality (1). Liver cirrhosis is

Correspondence to: Dr Xian-Jun Yu, Laboratory of Chinese Herbal Pharmacology, Oncology Center, Renmin Hospital and School of Basic Medical Sciences, Hubei University of Medicine, 30 South Renmin Road, Shiyan, Hubei 442000, P.R. China

E-mail: xjyu_hbmu@126.com

*Contributed equally

Key words: gambogenic acid, cancerous inhibitor of protein phosphatase 2A, hepatocellular carcinoma, proteasomal degradation, chemosensitivity believed to be the most significant risk factor for $70-90 \%$ of HCC patients (2). Moreover, viral infection, liver cytotoxicity, chronic inflammation, and many other factors have been implicated in HCC progression (3). Unfortunately, although some improvement has been achieved in the clinic, overall the prognosis is poor due to the development of resistance to chemotherapy and radiotherapy (4). Therefore, the development of novel targeted anticancer agents is extremely important to overcome this disease.

Cancerous inhibitor of protein phosphatase 2A (CIP2A) stabilizes the c-Myc protein via suppressing the protein phosphatase 2A (PP2A) (5). It has been reported to be amplified or overexpressed in a wide variety of human malignancies, such as gastric (6), breast (7), renal cell (8), bladder (9), and lung (10) cancer. The functional roles of CIP2A involve cell growth, cell invasion, drug resistance, and tumor formation (10-12). Several compounds from traditional Chinese medicine have been reported to exhibit anticancer activity via degradation of CIP2A and subsequent inactivation of AKT $(13,14)$. These findings indicate that CIP2A could be a promising target for cancer chemotherapy.

The genus Garcinia is known for its rich variety of oxygenated and prenylated phenol derivatives. Gambogic acid is a major active component of gamboge isolated from the resin of Garcinia hanburyi, which has been shown to have potent anticancer activity and is authorized to be tested in clinical trails (15-18). Gambogenic acid (GEA) is another active component of gamboge which exhibits cytotoxicity and anti-inflammatory activity $(19,20)$. The molecular mechanisms that underlie the effects of GEA include induction of cell cycle arrest $(21,22)$, apoptosis $(21,23-27)$, autophagy $(22,28)$, necroptosis (29) and chemosensitivity $(29,30)$. Herein, we demonstrated that GEA induced rapid proteasome-mediated degradation of CIP2A. GEA also showed potent anticancer activity and enhanced the effect of chemotherapeutic agents against HCC.

\section{Materials and methods}

Chemicals and reagents. GEA was extracted from gamboges by Dr Quanbin Han as previously described (20), dissolved 
in dimethyl sulfoxide (DMSO; Sigma-Aldrich, St. Louis, MO, USA) to make a stock solution $(20 \mathrm{mM})$ and stored at $-20^{\circ} \mathrm{C}$. $\mathrm{NH}_{4} \mathrm{Cl}$ and 3-MA were purchased from Sigma-Aldrich. Cycloheximide (CHX) and nocodazole were obtained from Beyotime Institute of Biotechnology (Jiangsu, China). CellTiter 96 AQueous One Solution Cell Proliferation Assay and Z-VAD-FMK were obtained from Promega (Madison, WI, USA). Antibodies used in our study were as follows: anti- $\beta$-actin (Sigma-Aldrich); anti-CIP2A, c-Myc, ubiquitin (Santa Cruz Biotechnology); anti-pAKT $\left(\mathrm{Ser}^{473}\right)$ (Cell Signaling Technology); and anti-rabbit and anti-mouse HRP-conjugated secondary antibodies (Pierce). Detection was performed using a Chemiluminescent Western Blot Detection kit (Thermo Fisher Scientific, Rockford, IL, USA).

Cell culture. The human hepatoma cell lines Hep G2 and Bel-7402 were obtained from the American Tissue Culture Collection (ATCC; Manassas, VA, USA) and maintained in Dulbecco's modified Eagle's medium (DMEM; Gibco-BRL, Gaithersburg, MD, USA) supplemented with $10 \%$ fetal bovine serum (FBS; Biological Industries, Kibbutz Beit-Haemek, Israel), $100 \mathrm{U} / \mathrm{ml}$ penicillin, $100 \mu \mathrm{g} / \mathrm{ml}$ streptomycin, and $2 \mathrm{mM}$ glutamine (Invitrogen Life Technologies, Carlsbad, CA, USA). All cells were cultured in a humidified incubator at $37^{\circ} \mathrm{C}$ under $5 \% \mathrm{CO}_{2}$.

Cell viability assay. Cells were seeded in 96-well plates $\left(1 \times 10^{3}\right.$ cells/well $)$ and then exposed to the indicated agents. After incubation for the indicated time, cell viability assay was conducted using the cell titer assay. Cell growth curve was estimated using trypan blue dye exclusion.

Real-time reverse transcription-polymerase chain reaction $(R T-P C R)$. Total RNA was isolated from cells by using the TRIzol reagent (Invitrogen Life Technologies) according to the manufacturer's instructions. The first strand complementary DNA (cDNA) was synthesized using PrimeScript ${ }^{\mathrm{TM}} \mathrm{RT}$ reagent kit with gDNA Eraser (Takara, Dalian, China). Primers used for RT-PCR analysis of human CIP2A included sense, 5'-CCATATGCTCACTCAGATGATGT-3' and antisense, 5'-GTGTATCATCTCCACAGAGAGTT-3'; and for GAPDH sense, 5'-TCACCAGGGCTGCTTTTA-3' and antisense, 5'-AAGGTCATCCCTGAGCTGAA-3'. PCR products were separated on $1.5 \%$ agarose gels and stained with GoldView. To confirm CIP2A mRNA expression, real-time polymerase chain reaction (qRT-PCR) was performed using the SYBR Premix Ex Taq (Takara). The primers were as follows: CIP2A sense, 5'-TGCGGCACTTGGAGGTAATTTC-3' and antisense, 5'-AGCTCTACAAGGCAACTCAAGC-3'; actin sense, 5'-ATC GTCCACCGCAAATGCTTCTA-3' and antisense, 5'-AGC CATGCCAATCTCATCTTGTT-3'. The amplifications were performed as follows: $94^{\circ} \mathrm{C}$ for $10 \mathrm{~min}$ and then 40 cycles of $94^{\circ} \mathrm{C}$ for $15 \mathrm{sec}, 60^{\circ} \mathrm{C}$ for $30 \mathrm{sec}$ and $72^{\circ} \mathrm{C}$ for $30 \mathrm{sec}$. Quantified values for gene expression were generated by the relative quantification method.

siRNA assays. Cells were transfected with double-stranded siRNA oligonucleotides $(100 \mathrm{nM})$ in 6-well plates using Lipofectamine 2000 (Invitrogen Life Technologies) according to the manufacturer's instructions. The sequences of siRNAs are as follows: CIP2A siRNA, 5'-GGUGCACGUUUCAUC AAUU-3'; NC siRNA, 5'-GGUGCACGUUUCAUCAAUU-3'.

Western blotting. Cells were suspended in lysis buffer containing $50 \mathrm{mM}$ Tris- $\mathrm{HCl}$ (pH 7.6), $150 \mathrm{mM} \mathrm{NaCl}, 1 \%$ NP40, $1 \mathrm{mM}$ EDTA, $1 \mathrm{mM} \mathrm{Na}_{3} \mathrm{VO}_{4}, 1 \mathrm{mM} \mathrm{NaF}$, and a cocktail of $1 \mathrm{mM}$ PMSF and $1 \mathrm{mM}$ protease inhibitors. The lysates were centrifuged at $12,000 \mathrm{x}$ g for $10 \mathrm{~min}$ at $4^{\circ} \mathrm{C}$, followed by measurements of protein concentrations using Pierce BCA Protein Assay Kit (Thermo Fisher Scientific). The supernatants were collected as NP40-soluble fractions. The pellets (NP40-insoluble fractions) were lysed in lysis buffer containing $2 \%$ SDS and boiled at $100^{\circ} \mathrm{C}$ for $7 \mathrm{~min}$ and chilled on ice. Proteins $(20 \mu \mathrm{g})$ were separated on $10 \%$ SDS-PAGE gel and transferred to PVDF membranes (Millipore Corp., Billerica, MA, USA). The membranes were incubated overnight with specific primary antibodies at $4^{\circ} \mathrm{C}$ after being blocked with $5 \%$ non-fat milk. After being washed three times with PBS containing $0.05 \%$ Tween-20 (PBST), the membranes were incubated with HRP-conjugated secondary antibodies for $1 \mathrm{~h}$ at room temperature, followed by 3 -times washing with $0.05 \%$ Tween-20/PBS and then detected using chemiluminescent substrate.

Statistical analysis. Quantitative data are presented as means \pm SED from triplicate experiments. Comparison between groups was performed by ANOVA and $\mathrm{P} \leq 0.05$ was considered to indicate a statistically significant difference.

\section{Results}

GEA triggers degradation of CIP2A. We aimed to ascertain whether GEA (Fig. 1A) affects CIP2A protein expression. We demonstrated that following treatment with GEA at $2.5 \mu \mathrm{M}$ for 2-12 h, a dramatic decrease in CIP2A expression in Hep G2 cells was observed (Fig. 1B). Similarly, treatment with GEA at 1.0-2.5 $\mu \mathrm{M}$ for $12 \mathrm{~h}$ decreased the CIP2A expression in a dose-dependent manner (Fig. 1B). These observations were further confirmed in Bel-7402 cells (Fig. 1C). Treatment with GEA at $2.5 \mu \mathrm{M}$ for $6-12 \mathrm{~h}$ also suppressed CIP2A in other hepatocellular carcinomas (Hep 3B, HuH-7), lung (A549), breast (MCF-7) and colon (HT-29) cancer cell lines, indicating that GEA-induced CIP2A downregulation is not cell-type specific (Fig. 1D).

GEA downregulates CIP2A at the post-transcriptional level.In order to clarify the underlying mechanism involved in CIP2A downregulation, RT-PCR assays were performed and revealed that GEA at $2.5 \mu \mathrm{M}$ for $6 \mathrm{~h}$ did not exhibit inhibitory effects on the expression of CIP2A mRNA in Hep G2 cells (Fig. 2A). These similar observations were confirmed by quantitative RT-PCR (Fig. 2B). Since GEA-mediated downregulation of CIP2A is not associated with transcription, we hypothesized that the reduction in CIP2A might be due to protein stabilization and degradation. As shown in Fig. $2 \mathrm{C}$ and D, protein synthesis inhibitor CHX barely reduced the expression of CIP2A within $8 \mathrm{~h}$, however, the combination of GEA and CHX resulted in a marked reduction of CIP2A at the protein level within $4 \mathrm{~h}$. These results indicate that GEA decreased CIP2A at the post-transcription level. 


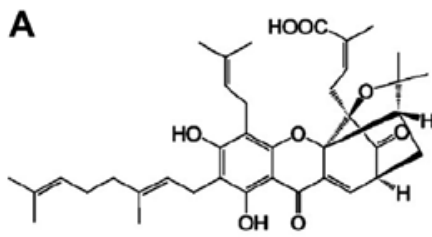

D

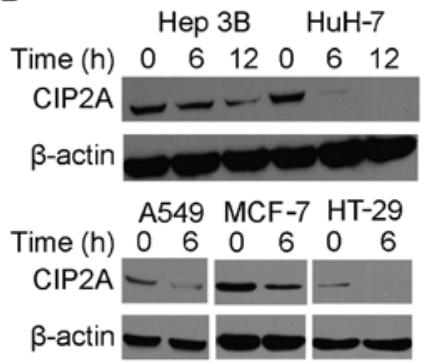

B

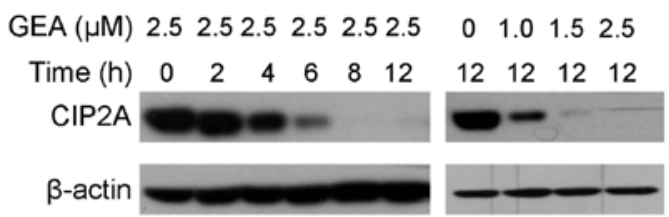

Hep G2

C

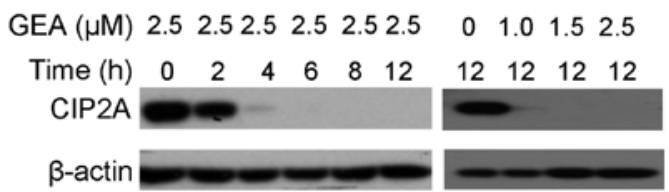

Bel-7402

Figure 1. GEA downregulates CIP2A. (A) Chemical structure of GEA. (B) Hep G2 and (C) Bel-7402 cells were treated with GEA at the indicated doses and time points, lysed and the expression of CIP2A was analyzed using the specific primary antibody. (D) Western blotting of lysates of various cancer cell lines treated with GEA. GEA, gambogenic acid; CIP2A, cancerous inhibitor of protein phosphatase $2 \mathrm{~A}$.
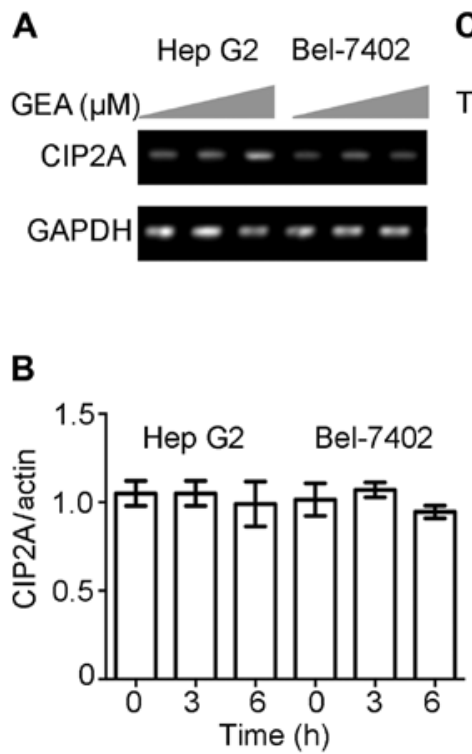

C

\section{$\mathrm{CHX}(50 \mu \mathrm{g} / \mathrm{ml}) \quad \mathrm{CHX}+\mathrm{GEA}$}

Time (h) $\begin{array}{cccccccccccc}0 & 1 & 2 & 4 & 6 & 8 & 0 & 1 & 2 & 4 & 6 & 8\end{array}$

CIP2A - - - - - $=0=-\cdots$

$\beta$-actin

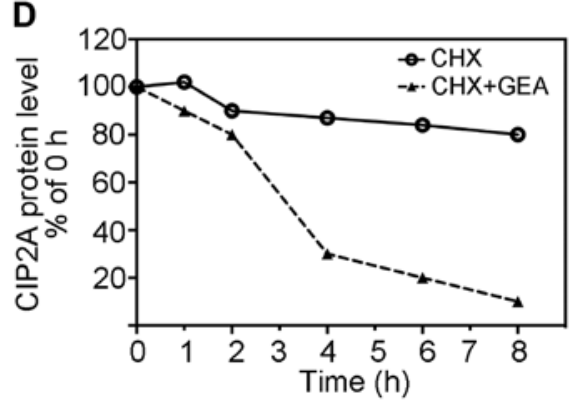

Figure 2. GEA downregulates CIP2A at the post-translational level. (A) Hep G2 cells were treated with $2.5 \mu \mathrm{M}$ GEA for 3 and 6 h, and then expression of CIP2A mRNA was detected by RT-PCR. (B) The mRNA expression of CIP2A was assayed by quantitative RT-PCR. (C) Hep G2 cells were treated with $50 \mu \mathrm{g} /$ $\mathrm{ml} \mathrm{CHX}$ or the combination of $\mathrm{CHX}$ and GEA $(2.5 \mu \mathrm{M})$, harvested at the indicated time points, and western blotting was performed to detect the protein expression of CIP2A. (D) Protein expression was quantified by densitometric analysis and normalized against $\beta$-actin expression. GEA, gambogenic acid; CIP2A, cancerous inhibitor of protein phosphatase 2A; RT-PCR, reverse transcription-polymerase chain reaction; CHX, cycloheximide.

GEA triggers ubiquitin-proteasome-mediated degradation of $C I P 2 A$. Four major proteolytic systems mediate protein stability: caspase, calpain, lysosome and proteasome (31). The caspase family of cysteine proteases is involved in cell death and cleavage of substrate proteins (32). Hep G2 cells were pre-treated with pan-caspase inhibitor Z-VAD-fmk (Z-VAD) for $2 \mathrm{~h}$, followed by treatment with or without GEA for $6 \mathrm{~h}$. However, no significant reversal effect was observed in the presence of Z-VAD (Fig. 3A). Calpains represent a well-conserved family of calcium-dependent cysteine proteases (33). We then pre-treated Hep G2 cells with calpain inhibitor III MDL-28170 (MDL), and the degradation of CIP2A was not reversed (Fig. 3B). Lysosomes and autophago- somes are organelles which play a central role in the control of cell fate (34). The Hep G2 cells were pretreated with a lysosomal protease inhibitor $\left(\mathrm{NH}_{4} \mathrm{Cl}\right)$ and an autophagy inhibitor (3-MA) and then treated with GEA. The two inhibitors did not prevent GEA-induced CIP2A degradation (Fig. 3C and D). The ubiquitin-proteasome pathway plays an important role in intracellular proteolysis $(35,36)$. Interestingly, we found that following treatment with the proteasome inhibitor MG132 or PSI alone, the expression of CIP2A in the Hep G2 cells was not affected within $6 \mathrm{~h}$ (Fig. 3E). However, the combination of MG132/PSI and GEA markedly impaired CIP2A degradation (Fig. 3E). Previous studies have reported that the proteasome inhibitor promotes accumulation of ubiquitinated 
A

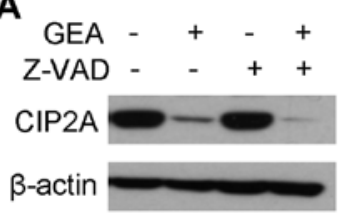

D

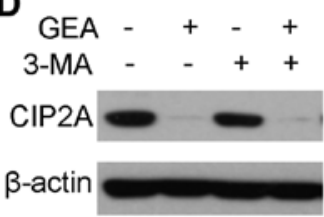

$\mathbf{F}$

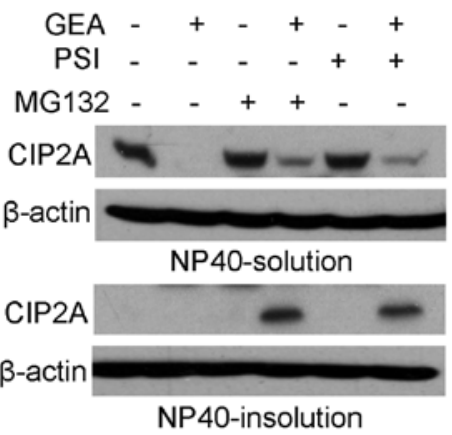

B

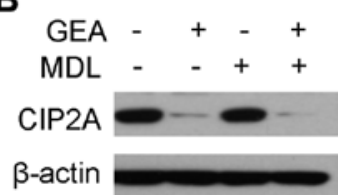

C

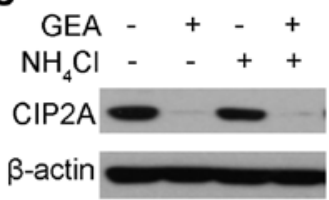

E

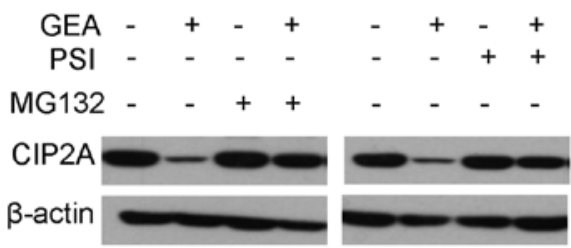

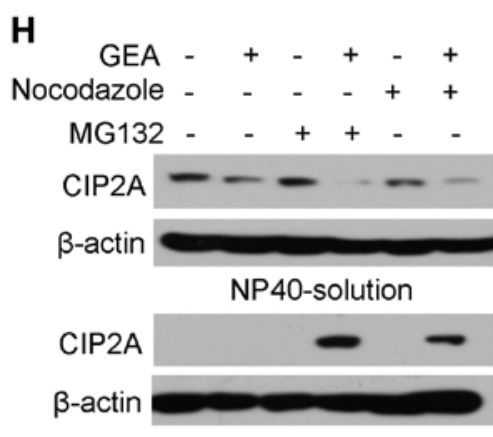

NP40-insolution

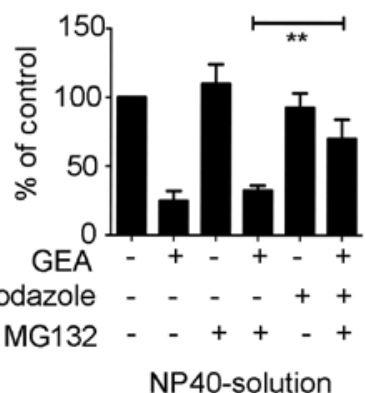

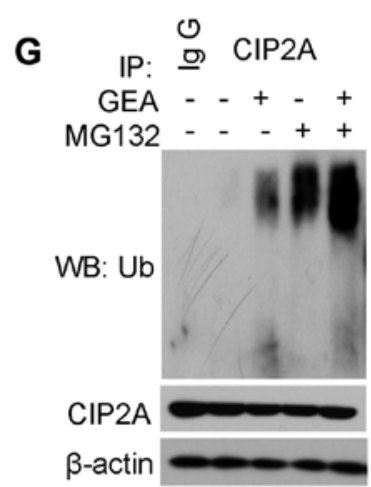

Figure 3. GEA triggers ubiquitin proteasome-mediated degradation of CIP2A. (A-D) Hep G2 cells were pre-treated with (A) Z-VAD (20 $\mu$ M), (B) MDL $(40 \mu \mathrm{M}),(\mathrm{C}) \mathrm{NH}_{4} \mathrm{Cl}(20 \mathrm{mM})$, (D) 3-MA $(10 \mathrm{mM})$ for $2 \mathrm{~h}$, followed by GEA treatment $(2.5 \mu \mathrm{M})$ for $6 \mathrm{~h}$ and the protein level of CIP2A was detected. (E) Hep G2 cells were pre-treated with MG132 $(10 \mu \mathrm{M})$ or PSI $(10 \mu \mathrm{M})$ for $2 \mathrm{~h}$, followed by GEA treatment $(2.5 \mu \mathrm{M})$ for $6 \mathrm{~h}$. Cell lysates were subjected to western blotting using the anti-CIP2A antibody. (F) Hep G2 cells were treated with MG132 $(10 \mu \mathrm{M})$ or PSI $(10 \mu \mathrm{M})$ for $2 \mathrm{~h}$ prior to GEA treatment for $6 \mathrm{~h}$. Cells were harvested and lysed in non-NP40 lysis buffer. The soluble and insoluble fractions were separated, boiled in SDS buffer for 10 min, and analyzed. Protein expression was quantified by densitometric analysis and normalized against $\beta$-actin expression. (G) Effect of GEA on CIP2A ubiquitination. Hep G2 cells were pre-treated with MG132 $(10 \mu \mathrm{M})$ for $2 \mathrm{~h}$, followed by GEA treatment for $1 \mathrm{~h}$. NP40-insoluble fractions were extracted as described above and subjected to immunoprecipitation with the CIP2A antibody, followed by western blotting using ubiquitin antibody against ubiquitinated CIP2A. (H) Effect of GEA on aggresome formation in the presence of proteasome inhibitor MG132. Hep G2 cells were pre-treated with MG132 (10 $\mu \mathrm{M})$ and/or nocodazole (20 $\mu \mathrm{g} / \mathrm{ml})$ for $2 \mathrm{~h}$, followed by GEA incubation $(2.5 \mu \mathrm{M})$ for $6 \mathrm{~h}$. The soluble and insoluble fractions were separated in cell lysis, and then analyzed by western blotting. Protein expression was quantified by densitometric analysis and normalized against $\beta$-actin expression. GEA, gambogenic acid; CIP2A, cancerous inhibitor of protein phosphatase $2 \mathrm{~A}$. Data are presented as means $\pm \mathrm{SEM} .{ }^{* *} \mathrm{P}<0.01,{ }^{* * *} \mathrm{P}<0.001$.

proteins and shifts them into detergent-insoluble cellular fractions, suggestive for aggresomes (37). To determine the distribution of CIP2A, Hep G2 cells were pre-treated with MG132 followed by GEA treatment. The results showed that accumulation of CIP2A in NP40 was induced in the insoluble fractions, while it had minimal effect on GEA-treated controls (Fig. 3F). Similar results were noted with GEA in combination with PSI in the Hep G2 cells (Fig. 3F). To further elucidate the molecular mechanism underlying the above process, we immunoprecipitated CIP2A from the NP40-insoluble fraction after treatment with GEA alone, MG132 alone, or their combinations. Notably, GEA alone was able to accumulate the ubiquitinated CIP2A (Fig. 3G, lane 3). Most importantly, these effects were enhanced following treatment with the combination of MG132 and GEA (Fig. 3G, lane 5). Aggresome formation is related to redistribution of the intermediate filament protein and blocked by microtubule depolymerizing $(38,39)$. We showed that microtubule depolymerizing agent nocodazole prevented the levels of CIP2A in the NP40 insoluble fraction (Fig. 3H, lane 6 vs. 4). Expectedly, an increase in CIP2A levels was detected in the NP40-soluble fraction (Fig. 3H, lane 6 vs. 4). These results suggest that GEA stimulates ubiquitin proteasome-mediated degradation of CIP2A. 

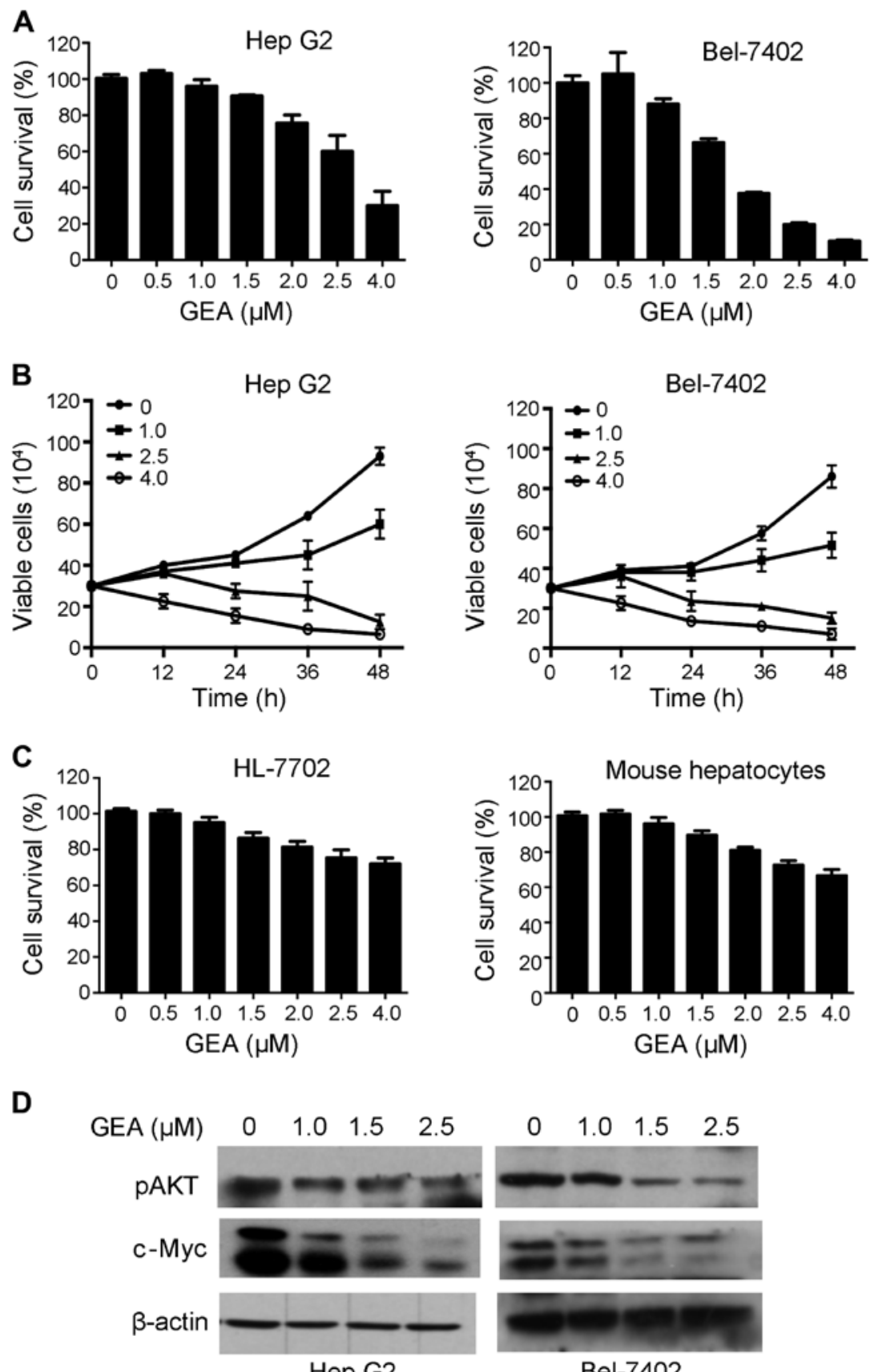

Figure 4. Inhibitory effects of GEA on HCC cell lines and CIP2A-downstream molecules. (A) Hep G2 and Bel-7402 cells were treated with the indicated concentrations of GEA for $24 \mathrm{~h}$, and the cell proliferation was determined using the CellTiter assay. (B) The cells were treated with the indicated concentrations of GEA for the indicated time points, and the cell viability was evaluated by trypan blue exclusion assay. (C) The human normal liver cell line HL-7702 and primary mouse hepatocytes were treated with GEA as indicated, and the cell proliferation was determined using CellTiter assay. (D) The cells were treated with different concentrations of GEA for $24 \mathrm{~h}$, and the protein levels of c-Myc and pAKT were observed by western blotting. GEA, gambogenic acid; HCC, human hepatocellular carcinoma; CIP2A, cancerous inhibitor of protein phosphatase 2A.

GEA suppresses cell proliferation and downregulates CIP2A-downstream molecules. CIP2A is a candidate therapeutic target and inhibition of its activity has potent anticancer effects (40). We therefore tested the effects of GEA on HCC cells, and found that GEA inhibited cell proliferation in a dose- and time-dependent manner (Fig. 4A and B). To determine whether GEA is more sensitive to tumor than normal cells, we examined the effect of GEA on normal human hepatocyte HL-7702 and mouse primary hepatocyte cells. We found that its cytotoxic effects on normal liver cells was weak (Fig. 4C), suggesting that GEA selectively affects tumor cells. Previous studies have demonstrated that CIP2A may activate AKT and modulate c-Myc stability (41). We therefore detected the effects of GEA on c-Myc and pAKT. We found that GEA markedly dowregulated c-Myc and pAKT in the Hep G2 and Bel-7402 cell lines (Fig. 4D). These results indicate that CIP2A-pAKT may play an important role in the inhibitory effect of GEA against tumor cells.

GEA and CIP2A silencing enhance the sensitivity to chemotherapeutic agents. Previous studies demonstrated that CIP2A overexpression is associated with drug resistance $(12,42)$. AKT 

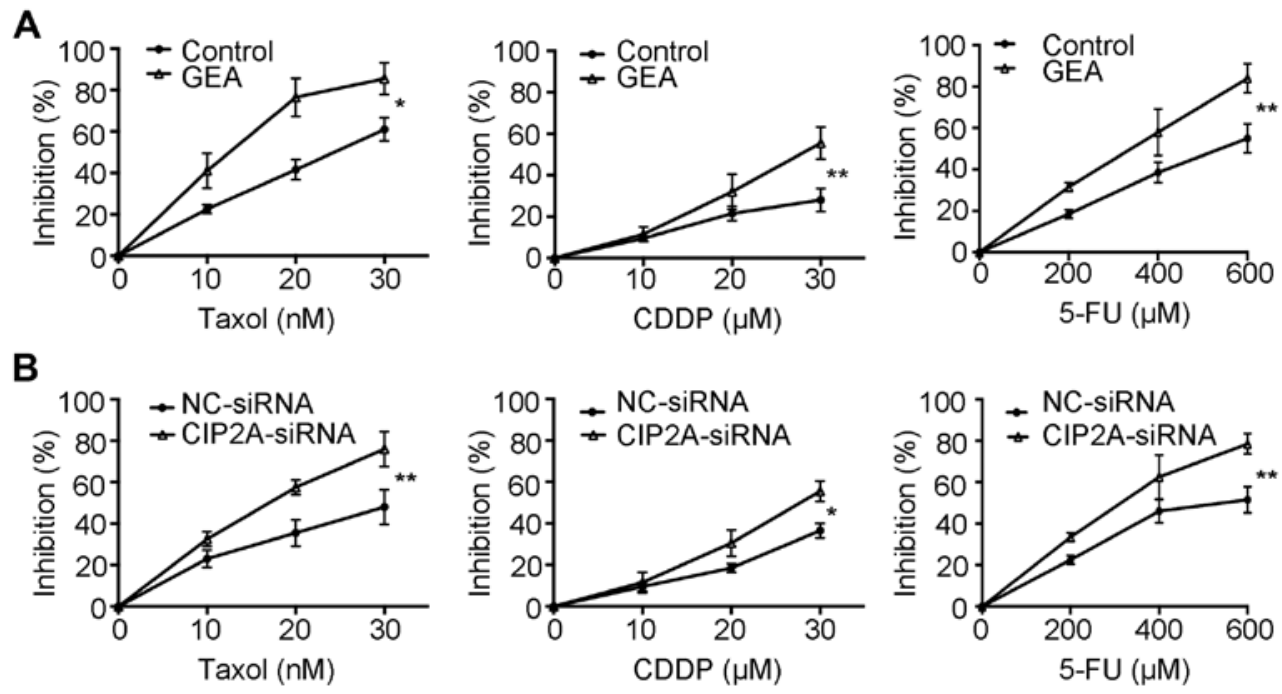

Figure 5. GEA enhances the sensitivity to chemotherapeutic agents. (A) Hep G2 cells were pre-treated with GEA (2.5 $\mu \mathrm{M})$ for $6 \mathrm{~h}$. The supernatant was discarded and chemotherapeutic agents were added at the indicated concentrations. After $24 \mathrm{~h}$, the cell viability was determined using CellTiter assay. (B) Hep G2 cells were transfected with $50 \mathrm{nM} \mathrm{CIP} 2 \mathrm{~A}$-siRNA or NC-siRNA for $48 \mathrm{~h}$. After $24 \mathrm{~h}$, the cells were treated with chemotherapeutic agents at the indicated concentrations for $24 \mathrm{~h}$, and the cell viability was determined by CellTiter assay. GEA, gambogenic acid; CIP2A, cancerous inhibitor of protein phosphatase 2A. Data are presented as means $\pm \mathrm{SEM}$. ${ }^{\mathrm{P}} \mathrm{P}<0.05,{ }^{* *} \mathrm{P}<0.01$ vs. the control group.

is a key mediator of cell survival and resistance to chemotherapy (43). We then proceeded to evaluate whether GEA enhances chemosensitivity. Our data showed that pre-treatment with GEA increased the cytotoxic effects compared to treatment with Taxol, cisplatin (CDDP) and 5-fluorouracil (5-FU) alone, respectively (Fig. 5A). We next explored the role of CIP2A in GEA-induced sensitivity in HCC. We showed that knockdown of CIP2A also enhanced the sensitivity of HCC to chemotherapy agents (Fig. 5B). These results imply that GEA sensitizes HCC to chemotherapy, and this effect is associated with CIP2A expression.

\section{Discussion}

CIP2A is strongly implicated in carcinogenesis which is associated with cigarette smoking and Helicobacter pylori infection, suggesting that CIP2A can serve as an indicator for assessing the potential carcinogenic risk $(10,44)$. Furthermore, overexpression of CIP2A is associated with drug resistance and tumor formation. Moreover, overexpression of CIP2A is frequently noted in most human cancers, and implies an indicator of poor clinical outcomes $(5,12)$. CIP2A-targeting compounds such as bortezomib (12), ethoxysanguinarine (13), and celastrol (14) exert chemopreventive effects. Herein, we report that GEA is a new CIP2A inhibitor which enhances the chemosensitivity of HCC to chemotherapeutic agents. We further showed that GEA triggered degradation of CIP2A in HCC, lung, breast and colon cancer cell lines (Fig. 1). Since CIP2A can be regulated at the transcriptional and post-transcription levels, subsequent data demonstrated that GEA did not inhibit CIP2A mRNA, but decreased the half-life of CIP2A protein (Fig. 2). These results suggest that GEA induced proteolytic degradation of CIP2A.

We further explored the mechanisms underlying the GEA-induced CIP2A degradation. Protein instability and degradation, such as caspase or calpain cleavage, lysosomal or autophagic protein degradation, and proteasome-mediated degradation, play a critical role in proteolysis (31). We focused on these and found that proteasome inhibitors impaired the GEA-induced CIP2A degradation, while inhibitors of caspases, calpain, lysosomes and autophagosomes had no effect on GEA-induced CIP2A degradation (Fig. 3A-E). Emerging evidence previously showed that proteasome inhibitors promote the accumulation of ubiquitinated CIP2A and aggresome formation (14). We observe herein that the proteasome inhibitors were able to protect CIP2A from GEA-mediated degradation (Fig. 3F). This phenomenon may be associated with accumulation of insoluble ubiquitinated CIP2A, leading to their aggregation and deposition in detergent-insoluble fractions (12). Indeed, treatment with GEA or MG132 induced accumulation of ubiquitinated CIP2A (Fig. 3G). Importantly, a significant increase was observed following co-treatment with GEA and MG132 (Fig.3G). These results further confirmed that GEA is a proteasome inhibitor and GEA treatment promotes CIP2A ubiquitination and accumulation. Previous evidence revealed that aggresome formation is associated with microtubule disruption (38). Consistent with this, our study found that microtubule depolymerizing agent nocodazole suppressed CIP2A aggregation in NP40-insoluble fractions (Fig. 3H). In addition, the levels of CIP2A were significantly enhanced in the NP40-soluble fractions, suggesting that aggresome formation is an important process in GEA-triggered degradation of CIP2A (Fig. 3H). Collectively, we speculate that proteasome inhibition may cause protein misfolding and aggregation, leading to accumulation of ubiquitinated CIP2A in NP40-insoluble fractions. These findings partially indicate that GEA-induced CIP2A degradation is mediated by the ubiquitin-proteasome pathway, but the detailed mechanisms, including the binding type (directly or indirectly), sites and the E3 ligase remain unclear and warrant further investigation.

Several studies have shown that GEA has a potent anticancer effect in various cancer cells in vitro and in vivo. However, the mechanisms underlying the anticancer activity 
remain unclear. Herein, we showed that GEA suppressed the proliferation and cell growth in HCC cell lines, but had a mild effect on normal liver cells (Fig. 4A-C). Interestingly, the expression of CIP2A-downstream molecules c-Myc and pAKT were impaired in cells following GEA treatment (Fig. 4D). These findings suggest that GEA potentiates the inhibitory effect via affecting the CIP2A-pAKT signaling pathway. Recent evidence suggests that bortezomib serves as a CIP2A inhibitor and enhances the effect of radiotherapy dependent on the CIP2A-PP2A-AKT signaling network, indicating that CIP2A may be associated with drug resistance (12). GEA was found to synergize with the cytotoxicity of chemotherapeutic drugs (Fig. 5A). Importantly, CIP2A-silenced cells were also more sensitive to chemotherapeutic agents (Fig. 5B). These results indicate that GEA as a CIP2A-targeting inhibitor modulates CIP2A and enhances the sensitivity of HCC cells to multiple chemotherapeutic agents.

In summary, we provide initial evidence that GEA triggered the degradation of CIP2A in various cancer cell lines. This rapid degradation may be associated with the ubiquitin-proteasome pathway. In addition, GEA suppressed the CIP2A-pAKT pathway and enhanced sensitivity to chemotherapeutic agents. Our findings indicate that GEA is a novel CIP2A inhibitor that may have therapeutic potential in HCC. Admittedly, the detailed mechanisms of GEA-induced CIP2A degradation remain unclear and warrant further investigation.

\section{Acknowledgements}

We thank Dr Haibing Zhang and Dr Quanbin Han for the long-term support. This study was supported by grants from the National Natural Science Foundation of China (81502548), the Natural Science Foundation of Hubei Province of China (2015CFB210), the Natural Science Foundation of Hubei Provincial Department of Education (Q20152101), the Young Scientist Innovation Team Project of Hubei Colleges (T201510), the Scientific and Technological Project of Shiyan City of Hubei Province (15Y08), the Initial Project for Post-Graduates of Hubei University of Medicine (2014QDJZR09), the Foundation for Innovative Research Team of Hubei University of Medicine (2014 CXX02) and Thousand Young Talents Program of the Chinese government.

\section{References}

1. Wang X, Zhang A and Sun H: Power of metabolomics in diagnosis and biomarker discovery of hepatocellular carcinoma. Hepatology 57: 2072-2077, 2013.

2. Fattovich G, Giustina G, Christensen E, Pantalena M, Zagni I, Realdi G and Schalm SW: Influence of hepatitis delta virus infection on morbidity and mortality in compensated cirrhosis type B. The European Concerted Action on Viral Hepatitis (Eurohep). Gut 46: 420-426, 2000.

3. El Tayebi HM, Omar K, Hegy S, El Maghrabi M, El Brolosy M, Hosny KA, Esmat G and Abdelaziz AI: Repression of miR-17-5p with elevated expression of E2F-1 and c-MYC in non-metastatic hepatocellular carcinoma and enhancement of cell growth upon reversing this expression pattern. Biochem Biophys Res Commun 434: 421-427, 2013.

4. Fujino H, Kimura T, Aikata H, Miyaki D, Kawaoka T, Kan H, Fukuhara T, Kobayashi T, Naeshiro N, Honda Y, et al: Role of 3-D conformal radiotherapy for major portal vein tumor thrombosis combined with hepatic arterial infusion chemotherapy for advanced hepatocellular carcinoma. Hepatol Res 45: 607-617, 2015
5. Junttila MR, Puustinen P, Niemelä M, Ahola R, Arnold H, Böttzauw T, Ala-aho R, Nielsen C, Ivaska J, Taya Y, et al: CIP2A inhibits PP2A in human malignancies. Cell 130: 51-62, 2007.

6. Li W, Ge Z, Liu C, Liu Z, Björkholm M, Jia J and Xu D: CIP2A is overexpressed in gastric cancer and its depletion leads to impaired clonogenicity, senescence, or differentiation of tumor cells. Clin Cancer Res 14: 3722-3728, 2008.

7. Côme C, Laine A, Chanrion M, Edgren H, Mattila E, Liu X, Jonkers J, Ivaska J, Isola J, Darbon JM, et al: CIP2A is associated with human breast cancer aggressivity. Clin Cancer Res 15: 5092-5100, 2009.

8. Basile JR and Czerninski R: The role of CIP2A in oral squamous cell carcinoma. Cancer Biol Ther 10: 700-702, 2010.

9. Huang LP, Savoly D, Sidi AA, Adelson ME, Mordechai E and Trama JP: CIP2A protein expression in high-grade, high-stage bladder cancer. Cancer Med 1: 76-81, 2012.

10. Ma L, Wen ZS, Liu Z, Hu Z, Ma J, Chen XQ, Liu YQ, $\mathrm{Pu}$ JX, Xiao WL, Sun HD, et al: Overexpression and small molecule-triggered downregulation of CIP2A in lung cancer. PLoS One 6: e20159, 2011.

11. Ren J, Li W, Yan L, Jiao W, Tian S, Li D, Tang Y, Gu G, Liu H and $\mathrm{Xu} \mathrm{Z}$ : Expression of CIP2A in renal cell carcinomas correlates with tumour invasion, metastasis and patients' survival. Br J Cancer 105: 1905-1911, 2011.

12. Huang CY, Wei CC, Chen KC, Chen HJ, Cheng AL and Chen KF: Bortezomib enhances radiation-induced apoptosis in solid tumors by inhibiting CIP2A. Cancer Lett 317: 9-15, 2012.

13. Liu Z, Ma L, Wen ZS, Cheng YX and Zhou GB: Ethoxysanguinarine induces inhibitory effects and downregulates CIP2A in lung cancer cells. ACS Med Chem Lett 5: 113-118, 2014.

14. Liu Z, Ma L, Wen ZS, Hu Z, Wu FQ, Li W, Liu J and Zhou GB: Cancerous inhibitor of PP2A is targeted by natural compound celastrol for degradation in non-small-cell lung cancer. Carcinogenesis 35: 905-914, 2014.

15. Pandey MK, Sung B, Ahn KS, Kunnumakkara AB, Chaturvedi MM and Aggarwal BB: Gambogic acid, a novel ligand for transferrin receptor, potentiates TNF-induced apoptosis through modulation of the nuclear factor-kappaB signaling pathway. Blood 110: 3517-3525, 2007.

16. Wang X, Chen Y, Han QB, Chan CY, Wang H, Liu Z, Cheng CH, Yew DT, Lin MC, He ML, et al: Proteomic identification of molecular targets of gambogic acid: Role of stathmin in hepatocellular carcinoma. Proteomics 9: 242-253, 2009.

17. Wang J, Chi Y, Zhan XK, Xie GR, Wang ZZ, Xiao W, Wang YG, $\mathrm{Hu} \mathrm{JF}$, Yu H, Yang L, et al: An open-labeled, randomized, multicentered, phase IIa study for advanced cancer treatment by gambogic acid injection (THS). J Clin Oncol 29: e13095, 2011.

18. Chi Y, Wang J, Zhan X, Xie G, Wang Z, Xiao W, Wang Y, Hu J, Yu H, Yang L, et al: p53 open-label, randomised, multicentre, phase 2a study of gambogic acid injection (THS) for treatment of advanced cancer. EJC Suppl 9: 21, 2011.

19. Yu X, Zhao Q, Zhang H, Fan C, Zhang X, Xie Q, Xu C, Liu Y, Wu X, Han Q, et al: Gambogenic acid inhibits LPS-simulated inflammatory response by suppressing NF- $\kappa \mathrm{B}$ and MAPK in macrophages. Acta Biochim Biophys Sin (Shanghai) 48: 454-461, 2016.

20. Han QB, Wang YL, Yang L, Tso TF, Qiao CF, Song JZ, Xu LJ, Chen SL, Yang DJ and Xu HX: Cytotoxic polyprenylated xanthones from the resin of Garcinia hanburyi. Chem Pharm Bull (Tokyo) 54: 265-267, 2006.

21. Li Q, Cheng H, Zhu G, Yang L, Zhou A, Wang X, Fang N, Xia L, Su J, Wang M, et al: Gambogenic acid inhibits proliferation of A549 cells through apoptosis-inducing and cell cycle arresting. Biol Pharm Bull 33: 415-420, 2010.

22. Yu XJ, Han QB, Wen ZS, Ma L, Gao J and Zhou GB: Gambogenic acid induces G1 arrest via GSK3 $\beta$-dependent cyclin D1 degradation and triggers autophagy in lung cancer cells. Cancer Lett 322: 185-194, 2012.

23. Cheng H, Su JJ, Peng JY, Wang M, Wang XC, Yan FG, Wang XS and Li QL: Gambogenic acid inhibits proliferation of A549 cells through apoptosis inducing through up-regulation of the p38 MAPK cascade. J Asian Nat Prod Res 13: 993-1002, 2011.

24. Yan F, Wang M, Chen H, Su J, Wang X, Wang F, Xia L and Li Q: Gambogenic acid mediated apoptosis through the mitochondrial oxidative stress and inactivation of Akt signaling pathway in human nasopharyngeal carcinoma CNE-1 cells. Eur J Pharmacol 652: 23-32, 2011.

25. Chen HB, Zhou LZ, Mei L, Shi XJ, Wang XS, Li QL and Huang L: Gambogenic acid-induced time- and dose-dependent growth inhibition and apoptosis involving Akt pathway inactivation in U251 glioblastoma cells. J Nat Med 66: 62-69, 2012. 
26. Yan F, Wang M, Li J, Cheng H, Su J, Wang X, Wu H, Xia L, Li X, Chang HC, et al: Gambogenic acid induced mitochondrial-dependent apoptosis and referred to phospho-Erk1/2 and phospho-p38 MAPK in human hepatoma HepG2 cells. Environ Toxicol Pharmacol 33: 181-190, 2012.

27. Zhou J, Luo YH, Wang JR, Lu BB, Wang KM and Tian Y: Gambogenic acid induction of apoptosis in a breast cancer cell line. Asian Pac J Cancer Prev 14: 7601-7605, 2013.

28. Mei W, Dong C, Hui C, Bin L, Fenggen Y, Jingjing S, Cheng P, Meiling S, Yawen H, Xiaoshan W, et al: Gambogenic acid kills lung cancer cells through aberrant autophagy. PLoS One 9: e83604, 2014.

29. Su J, Cheng H, Zhang D, Wang M, Xie C, Hu Y, Chang HC and Li Q: Synergistic effects of 5-fluorouracil and gambogenic acid on A549 cells: Activation of cell death caused by apoptotic and necroptotic mechanisms via the ROS-mitochondria pathway. Biol Pharm Bull 37: 1259-1268, 2014.

30. He Y, Ding J, Lin Y, Li J, Shi Y, Wang J, Zhu Y, Wang K and $\mathrm{Hu} \mathrm{X}$ : Gambogenic acid alters chemosensitivity of breast cancer cells to Adriamycin. BMC Complement Altern Med 15: 181, 2015.

31. Wang Y and Zhang Y: Regulation of TET protein stability by calpains. Cell Reports 6: 278-284, 2014.

32. Cohen GM: Caspases: The executioners of apoptosis. Biochem J 326: 1-16, 1997.

33. Storr SJ, Carragher NO, Frame MC, Parr T and Martin SG: The calpain system and cancer. Nat Rev Cancer 11: 364-374, 2011.

34. Medina DL, Di Paola S, Peluso I, Armani A, De Stefani D, Venditti R, Montefusco S, Scotto-Rosato A, Prezioso C, Forrester A, et al: Lysosomal calcium signalling regulates autophagy through calcineurin and TFEB. Nat Cell Biol 17: 288-299, 2015.

35. Shen M, Schmitt S, Buac D and Dou QP: Targeting the ubiquitin-proteasome system for cancer therapy. Expert Opin Ther Targets 17: 1091-1108, 2013.
36. Ciechanover A: Proteolysis: From the lysosome to ubiquitin and the proteasome. Nat Rev Mol Cell Biol 6: 79-87, 2005.

37. Wang J, Zhao Q, Qi Q, Gu HY, Rong JJ, Mu R, Zou MJ, Tao L, You QD and Guo QL: Gambogic acid-induced degradation of mutant p53 is mediated by proteasome and related to CHIP. J Cell Biochem 112: 509-519, 2011.

38. Johnston JA, Ward CL and Kopito RR: Aggresomes: A cellular response to misfolded proteins. J Cell Biol 143: 1883-1898, 1998.

39. Bence NF, Sampat RM and Kopito RR: Impairment of the ubiquitin-proteasome system by protein aggregation. Science 292 : 1552-1555, 2001

40. Khanna A, Rane JK, Kivinummi KK, Urbanucci A, Helenius MA, Tolonen TT, Saramäki OR, Latonen L, Manni V, Pimanda JE, et al: CIP2A is a candidate therapeutic target in clinically challenging prostate cancer cell populations. Oncotarget 6: 19661-19670, 2015.

41. Khanna A, Böckelman C, Hemmes A, Junttila MR, Wiksten JP, Lundin M, Junnila S, Murphy DJ, Evan GI, Haglund C, et al: MYC-dependent regulation and prognostic role of CIP2A in gastric cancer. J Natl Cancer Inst 101: 793-805, 2009.

42. Choi YA, Park JS, Park MY, Oh KS, Lee MS, Lim JS, Kim KI, Kim KY, Kwon J, Yoon DY, et al: Increase in CIP2A expression is associated with doxorubicin resistance. FEBS Lett 585: 755-760, 2011.

43. Jiao $M$ and Nan KJ: Activation of PI3 kinase/Akt/HIF-1 $\alpha$ pathway contributes to hypoxia-induced epithelial-mesenchymal transition and chemoresistance in hepatocellular carcinoma. Int J Oncol 40: 461-468, 2012.

44. Zhao D, Liu Z, Ding J, Li W, Sun Y, Yu H, Zhou Y, Zeng J, Chen $\mathrm{C}$ and Jia J: Helicobacter pylori CagA upregulation of CIP2A is dependent on the Src and MEK/ERK pathways. J Med Microbiol 59: 259-265, 2010. 